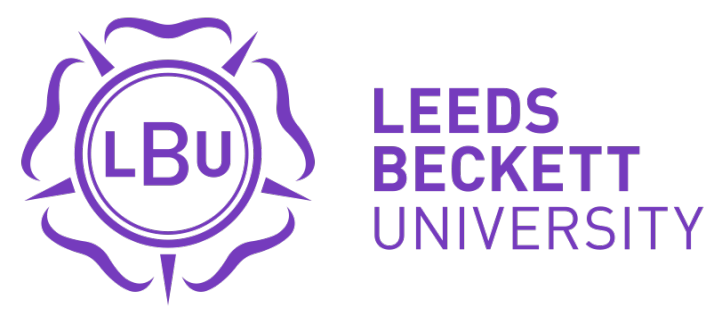

Citation:

Ajayi, SO and Oyedele, LO (2017) Policy Imperatives for Diverting Construction Waste from Landfill: Experts' recommendations for UK policy expansion. Journal of Cleaner Production, 147. pp. 57-65. ISSN 0959-6526 DOI: https://doi.org/10.1016/j.jclepro.2017.01.075

Link to Leeds Beckett Repository record:

https://eprints.leedsbeckett.ac.uk/id/eprint/3458/

Document Version:

Article (Accepted Version)

Creative Commons: Attribution-Noncommercial-No Derivative Works 4.0

The aim of the Leeds Beckett Repository is to provide open access to our research, as required by funder policies and permitted by publishers and copyright law.

The Leeds Beckett repository holds a wide range of publications, each of which has been checked for copyright and the relevant embargo period has been applied by the Research Services team.

We operate on a standard take-down policy. If you are the author or publisher of an output and you would like it removed from the repository, please contact us and we will investigate on a case-by-case basis.

Each thesis in the repository has been cleared where necessary by the author for third party copyright. If you would like a thesis to be removed from the repository or believe there is an issue with copyright, please contact us on openaccess@leedsbeckett.ac.uk and we will investigate on a case-by-case basis. 


\title{
Policy Imperatives for Diverting Construction Waste from Landfill: Experts' recommendations for UK policy expansion
}

\begin{abstract}
Legislation and fiscal policies have remained the key drivers of construction waste minimization. It has often been suggested that reducing waste to the landfill does not only require improvement on existing waste management policies and fiscal framework; there is a need for adequate inputs from the construction professionals. As a means of engendering effective waste management policies, this study explores industry practitioners' viewpoints on effective policies for minimising waste landfilled by the UK construction industry. Using exploratory sequential mixed method approach, qualitative and quantitative methods were used. In the first phase of the study, data was collected through focus group discussions with 24 experts from the UK construction industry. Findings from the qualitative study served as an input into a questionnaire, which was used to elicit a wider opinion from 63 experts at the quantitative stage of the study.
\end{abstract}

The study suggests that for waste management legislation and policies to effectively drive construction waste minimization, six key measures are important. These include (i) provision of tax breaks and incentives to good waste performers and waste management businesses; (ii) increased targeting of design stages in policies; (iii) Extension of sustainable design appraisal systems by allocating more points to proven waste performance measures; (iv) increased stringency of legislative measures by requiring use of proven waste efficient design, procurement and construction methods; (v) increased stringency of fiscal policies by increasing penalties for poor waste performance; and (vi) corroboration of policy requirements with enablers and facilitators. The strategies through which each of the legislative and fiscal measures could be tailored and enhanced are discussed in the paper. By embracing both stringent and palliative policy measures suggested in the study, substantial construction waste could be diverted from landfill.

Keywords: Waste management legislation; landfill; aggregate tax; incentives; design out waste; recycled materials; deconstruction plan; Sustainability policies; Construction management. 


\section{Introduction}

Among other environmental impacts of building and construction activities, increasing generation of construction waste is continuously raising concerns about environmental impacts, depletion of mineral resources and environmental health (Shen and Tam, 2002). Evidence shows that the construction industry generates about $35 \%$ of waste to landfill across the globe (Solís-Guzmán et al., 2009). In the UK, a 2013 figure suggests that out of 100\% of waste generated, $44 \%, 14 \%, 13 \%, 13 \%, 9 \%$ and $7 \%$ are due to construction, commercial, industrial, household, mining and agricultural activities respectively (DEFRA, 2013). As this means that the industry contributes the largest proportion of UK waste to landfill, similar patterns exist in other large economies (Oyedele et al., 2014). Construction activities in the US generates about $29 \%$ of landfill waste (Yu et al., 2013), while the industry landfills about $40 \%$, 44\%, 27\% and 25\% in Brazil, Australia, Canada and Hong Kong respectively (Lu and Tam, 2013; Oyedele et al., 2014). Albeit negative environmental impacts of waste, reducing construction waste could result in substantial financial gains. A study by the UK's Building Research Establishment (BRE) suggests that up to £130million is accruable to the UK economy by reducing just $5 \%$ of its construction waste (BRE, 2003). These savings are in forms of the cost of acquiring the wasted materials, cost of storage, cost of transportation and disposal as well as the landfill tax payable for waste disposal (Coventry and Guthrie, 1998).

The need to tap into this potential gains, and prevent impending negative environmental impacts, have challenged the industry, government, researchers and businesses operating within the industry (Adjei et al., 2013). This consequently influenced development of various waste preventive and management strategies, legislative and fiscal measures, construction technologies and project procurement approach. Despite all these measures, landfilling remains a popular way of treating waste generated by the industry (DEFRA, 2013; Oyedele et al., 2013). This suggests ineffectiveness in the way construction waste is currently managed (Ajayi et al., 2014). Notwithstanding the general criticism of existing waste management approaches (Yuan, 2013; Yuan and Shen, 2011), there is an understanding that little success in diverting waste from landfill is credited to legislative and fiscal provisions (Al-Hajj and Hamani, 2011; Pitt et al., 2009). However, there has been calls for increasing stringency of waste management legislations as a means of reducing waste landfilled by the construction industry (Ajayi et al., 2015). 


\subsection{Motivation for the study}

Albeit claims that there is a need for increasing the stringency of existing waste management legislation and fiscal measures (Ajayi et al., 2015; Pitt et al., 2009), there has been a paucity of literature that corroborates government's efforts in formulating or improving existing waste management strategies. This is notwithstanding the claims that most waste management legislations and fiscal provisions are made without inputs from the construction professionals (Tam, 2008). However, it is clear that effective and widely supported legislation requires adequate consultation of the stakeholders that are targeted by such legislations (Bingham et al., 2005).

Meanwhile, Intervention theory proposes that intervention could either seek to help the client system to achieve their potentials or to coerce them to do what the interveners' desires (Argyris, 1970). In the case of government intervention in construction waste management, the latter has usually been the case, especially as environmental awareness drives government's policy interventions (Al-Hajj and Hamani, 2011). As such, most waste management policies have been criticised by the industry's practitioners based on the perception that they were meant to coerce the experts (Ajayi et al., 2015). This is evident in the latest repealing of the site waste management legislation due to the outcry by the industry practitioners. In addition, while the intervention theory proposes the concept of free will that allows practitioners an opportunity to address waste management using the best possible options, this is not usually the case with most policies. Thus, it is important to explore practitioner-informed measures that are capable of engendering effectiveness of construction waste management policies.

\subsection{Aim and Objectives}

As such, this study aims at exploring construction professionals' views on effective policies for minimising waste landfilled by the construction industry. It seeks to corroborate government's efforts with expertise opinion of the industry's professionals, thereby enhancing wider acceptability as well as the effectiveness of any proposed legislative and fiscal measures.

The study fulfils its goals through the following objectives.

(1) To explore strategies for improving the effectiveness of existing waste management policies. (2) To identify a set of waste preventive measures that could be facilitated and driven by the government towards minimising waste to landfill 
(3) To suggest future direction for legislative and fiscal measures that are capable of reducing waste landfilled by the construction industry.

In addition to these objectives, the study also evaluates the relevance of intervention theory in addressing environmental issues. Findings of the study are related to the constructs of the theory.

\subsection{Overview of the empirical study}

As a means of ensuring in-depth exploration of strategies for improving waste management legislation, this study employed mixed method approach to data collection. Rather than limiting the respondents to a ranking of pre-determined factors, which may not be comprehensive enough, the study employs sequential exploratory technique. This thus ensures that new phenomenon unravelled during the first stage of the study are corroborated with further quantitative studies. As a means of preventing potential bias, descriptive interpretive research approach was used for the qualitative enquiry. Based on this, the study is limited to the viewpoints of the construction professionals who are impacted by the legislative measures, and not the government representatives who made the policies.

In order to lay background for the study, the next section reviews intervention theory and existing legislation and fiscal measures that are aimed at militating waste generation or landfilling by the construction industry. Methodological approach to enquiry, which includes research sampling, approach to data collection and method of data analysis, is then justified and discussed. Findings of the study are then enumerated and discussed before culminating the study with implication for legislative provisions and conclusion. The paper suggests legislative measures that could be considered by governments in efforts to stimulate waste diversion from landfill. Implementation of the suggested measures would ensure wide acceptance and effectiveness of waste management legislations, as the suggested measures emanated from experts within the construction industry.

\section{Waste Management Policies and Legislation}

Legislation and fiscal provision has remained an effective strategy for driving sustainable practices, including waste mitigation across nations (Pitt et al., 2009; Al-Hajj and Hamani, 2011). However, there has been cases whereby pressure was mounted on the government to repeal waste management 
legislation (Tam, 2008). This section reviews existing waste management legislation in the UK and, by extension, the EU.

\subsection{European Union (EU) Waste Management Legislation and Policy}

Among the EU waste management legislations, the Waste Framework Directive (2008/98/EC) is of significance to the construction industry. It requires that waste is managed without engendering human health and the environment, and by preventing risks to air, water, soil, animal and plants. The directive established the polluter-pays principle, which stipulates that cost of waste management should be paid by the polluter or by the current or previous waste holders. The directive further requires that waste legislation of the member states shall apply a priority ranging from prevention, preparing for re-use, recycling and other recovery, such as energy recovery, to disposal (Directive 2008/98/EC). The Waste Framework Directive, which favours preventive measures as the best approach to tackling waste, have been implemented in the UK through Waste Regulations (England and Wales) 2011.

Like the Waste Framework Directive, another EU legislative framework that significantly influences construction industry and its waste management is the Landfill Directive (1999/31/EC). It aims to achieve a conventional technical standard for locating, design, operation, maintenance, closure and aftercare of landfill sites. Using 1995 as a baseline, the Directives set targets of 75\%, 50\% and 35\% of biodegradable municipal solid waste for the year 2010, 2013 and 2020 respectively. This means that not more than 7.4million tonnes and 5.5million tonnes of biodegradable waste is to be landfilled in 2013 and 2020 respectively (DEFRA, 2007). The EU Landfill Directives (1999/31/EC) have been implemented in England through Waste Strategy (2007) and across the UK through Waste and Emission Trading Act (2003).

\subsection{Waste Targets}

As an improvement on targets set in 2000, the Waste Strategy for England (2007) set higher national waste reduction and management targets. While recycling and composting target for household waste was set at $40 \%$ for 2010, a target of $45 \%$ and 50\% were set for 2015 and 2020 respectively. Set at 53\% for 2010, recovery of municipal waste is targeted to reach $67 \%$ by 2015 and $75 \%$ by 2020 .

Since the construction industry accounts for the largest volume of waste generated in the UK, according to DEFRA (2007), the Waste Strategy for England (2007) stresses the need for discussion and consultation with construction stakeholders to halve construction waste to landfill. More specific to the construction industry, the Sustainable Construction Strategy (2008) sets overall targets for diverting 
construction and demolition waste from landfill (HM Government, 2008). Some of the targets include reduction of packaging waste by $20 \%$ as well as reuse and recycling of $70 \%$ of construction and demolition waste by 2020 .

\subsection{Fiscal Policies}

Penalties, fines and other fiscal provisions have remained an effective means of driving construction waste diversion from landfill. Highly effective among the fiscal measure is the landfill tax, which was introduced by the UK government in 1996 (Read et al., 1997). The overall goal of the landfill tax is to ensure that polluters pay for the cost of waste management. Also, it is a aimed at encouraging reuse and recycling of materials, thereby discouraging landfilling. Within the UK, landfill taxation has been based on unit pricing, where charges are paid per tonnage of waste disposed in the landfill. Since its start at the rate of $£ 7$ and $£ 2$ in 1996 , landfill tax has been upwardly reviewed to become $£ 82.60$ and $£ 2.60$ per tonnage of active and inert waste respectively. Because of its financial implications, evidence suggests that imposition of landfill tax has improved waste management among construction professionals in the UK and beyond (Ajayi et al., 2015).

Another similar fiscal provision that aimed at reducing construction waste and increasing materials reuse is the aggregate tax, which is a tax on gravel, sand and rock. In line with various waste diversion targets set by the UK government, imposition of aggregate tax is to ensure that aggregates are reused rather than depositing them in the landfill. Since its introduction at the rate of $£ 1.60$ per tonnage of virgin aggregates in 2001, aggregate tax has been upwardly reviewed, and it currently stands at $£ 2$ per tonnage since 2009 .

\section{Research Methodology}

Owing to the needs for exploring the concept of this study from practitioners' perspectives, sequential exploratory research method is employed. It involves initial exploration of research phenomenon, using qualitative data collection and analysis. The qualitative finding is then used in the second phase of the study, which involved quantitative data collection and analysis (Creswell, 2014).

\subsection{Qualitative Data Collection}

In the first phase of the study, a critical evaluation of the relevance of various types of qualitative research approaches supports an adoption of descriptive interpretive approach as a methodology for the study. This approach posits that a poorly conceptualised, widely neglected or inadequately explored concept could only be well understood by using qualitative approach to seek new meanings of the concept of enquiry (Van Manen, 1990). This study employed focus group discussions as a means of 
data collection. The focus group is particularly preferred to interviews as it allows the research participants to have intersubjective discourses, thereby building on each other's opinion and understanding (Kvale, 1996). Based on Merriam (1998) position that purposive sampling ensures adequate exploration of the concept of enquiry through purposefully selected participants, this study employed purposive sampling. The selection was based on job position, experience within the construction industry as well as interest or involvement in waste management.

Notwithstanding the use of purposive sampling, it was ensured that every major profession, involved from project planning to completion, is represented. A total of 24 experts participated in four focus group discussions used for the study. This falls in line with Polkinghorne's (1989) assertion that between five and 25 information-rich participants are required for a qualitative research. It was ensured that representatives of design architects, projects architects, design engineers, site engineers, project managers and materials suppliers were involved in the study. Materials suppliers were particularly involved in the study as evidence suggests that material procurement process could enhance waste minimization (Dainty and Brooke, 2004). Table 1 gives an overview of the participants involved in the focus group discussions.

Table 1: Overview of the focus group discussions and the participants

\begin{tabular}{|c|c|c|c|}
\hline$F G$ & Categories of the Participants & $\begin{array}{c}\text { Total No of } \\
\text { experts }\end{array}$ & $\begin{array}{c}\text { Years of } \\
\text { experience }\end{array}$ \\
\hline 1 & $\begin{array}{l}\text { Architects and Design Managers } \\
\text { - } 2 \text { design architects } \\
\text { - } 3 \text { site architects } \\
\text { - } 2 \text { design managers } \\
\end{array}$ & 7 & $7-18$ \\
\hline 2 & $\begin{array}{l}\text { Materials Suppliers and Supply Chain Managers } \\
\text { - } 4 \text { materials suppliers } \\
\text { - } 2 \text { supply chain managers }\end{array}$ & 6 & $11-21$ \\
\hline 3 & Construction Project Managers & 6 & $10-19$ \\
\hline 4 & $\begin{array}{l}\text { Civil and Structural Engineers } \\
\text { - } 1 \text { design engineer } \\
\text { - } 4 \text { site based engineers }\end{array}$ & 5 & $9-21$ \\
\hline \multicolumn{2}{|r|}{ Total } & 24 & \\
\hline
\end{tabular}

The participants were able to suggest measures for strengthening existing waste management legislations and policies as well as the new policy directions that could engender waste minimization in the construction industry. Each of the discussions lasted between 75 and 90 minutes, and they were recorded with permissions of the research participants. 


\subsection{Qualitative Data Analysis and Findings}

In order to ensure detail analysis of the data, the voice data was transcribed into written statement, which is read several times to identify themes that emanated from the discussions. While doing this, content driven thematic analysis was employed as it ensures identification of both implicit and explicit statements that emanated from the written data (Braun and Clarke, 2006). Using content driven thematic analysis, coding system in the data analytical process was facilitated through three categories of elements used in labelling the data. In addition to the respondents' comments, the three elements are code/keywords, discussion and measures. The codes/keywords identify the words through which a particular policy suggestion was identified, while the discussion marks the focus group discussion from which the suggestion is made. Measures mark out the waste management policies that are suggested by the participant. Table 2 shows the policies suggested by the groups of experts. As shown in Table 2, all factors were agreed upon by experts from at least two focus group discussions.

\section{Table 2: Policy directions for engendering construction waste minimization}

\begin{tabular}{|c|c|c|c|c|c|c|}
\hline \multirow{2}{*}{ SN } & \multirow{2}{*}{$\begin{array}{c}\text { Policy Suggestions (PS) for ensuring effectiveness of waste management legislations } \\
\text { and policies }\end{array}$} & \multicolumn{4}{|c|}{ Focus Groups } & \multirow{2}{*}{$\begin{array}{l}{ }^{b} \text { No of } \\
\text { codes }\end{array}$} \\
\hline & & 1 & 2 & 3 & 4 & \\
\hline PS1 & Allocation of more points to waste in design appraisal tools such as BREEAM ${ }^{\mathrm{a}}$ & $\checkmark$ & $\checkmark$ & $\checkmark$ & $\checkmark$ & 49 \\
\hline PS2 & Deconstructability and deconstruction plan as a part of design documents & & $\checkmark$ & $\checkmark$ & $\checkmark$ & 26 \\
\hline PS3 & Award of points for the use of steel hoarding, formworks and dry walling & $\checkmark$ & & $\checkmark$ & $\checkmark$ & 49 \\
\hline PS4 & Award of points for the use of Just in Time (JIT) Procurement system & $\checkmark$ & $\checkmark$ & $\checkmark$ & $\checkmark$ & 49 \\
\hline PS5 & $\begin{array}{l}\text { Integrate construction waste management into the assessment of construction } \\
\text { contractor }\end{array}$ & $\checkmark$ & & & $\checkmark$ & 18 \\
\hline PS6 & Employment of a dedicated site worker for waste management to be required & $\checkmark$ & $\checkmark$ & $\checkmark$ & $\checkmark$ & 7 \\
\hline PS7 & Take back scheme to become part of construction procurement requirements & $\checkmark$ & & $\checkmark$ & $\checkmark$ & 14 \\
\hline PS8 & Requirement for the use of a proportion of secondary materials in every projects & & $\checkmark$ & $\checkmark$ & & 22 \\
\hline PS9 & Raising fees for mixed wastes and reducing fees for separated waste disposal & $\checkmark$ & $\checkmark$ & $\checkmark$ & $\checkmark$ & 12 \\
\hline PS10 & Consider possibility of design freeze and contract completion before construction & $\checkmark$ & $\checkmark$ & $\checkmark$ & $\checkmark$ & 21 \\
\hline PS11 & Dimensional coordination \& specification of standard materials sizes to be required & $\checkmark$ & $\checkmark$ & $\checkmark$ & $\checkmark$ & 20 \\
\hline PS12 & Allocation of points for the use of pre-assembled/modular system for large-scale & $\checkmark$ & $\checkmark$ & $\checkmark$ & $\checkmark$ & 49 \\
\hline PS13 & Increasing aggregate tax and introduction of tax for disposing reusable materials & $\checkmark$ & $\checkmark$ & & $\checkmark$ & 24 \\
\hline PS14 & Increasing landfill disposal fee and use of the excess fees as incentives & $\checkmark$ & $\checkmark$ & $\checkmark$ & $\checkmark$ & 26 \\
\hline PS15 & Increased consideration of design stages rather than the actual construction & & $\checkmark$ & & $\checkmark$ & 58 \\
\hline PS16 & $\begin{array}{l}\text { Collaborative contractual system such as Integrated Project Delivery (IPD) to be } \\
\text { rewarded by points allocation }\end{array}$ & $\checkmark$ & $\checkmark$ & $\checkmark$ & $\checkmark$ & 9 \\
\hline PS17 & Enhance information about quality, availability and benefits of secondary materials & $\checkmark$ & $\checkmark$ & $\checkmark$ & $\checkmark$ & 13 \\
\hline PS18 & Improved database management for construction wastes and their reusability & $\checkmark$ & & $\checkmark$ & $\checkmark$ & 9 \\
\hline PS19 & Developing market structure and easy access to recycled materials & $\checkmark$ & $\checkmark$ & $\checkmark$ & $\checkmark$ & 11 \\
\hline PS20 & Requirement for display of content of recycled materials/contents in products & $\checkmark$ & & $\checkmark$ & $\checkmark$ & 9 \\
\hline PS21 & Tax break for waste treatment equipment & $\checkmark$ & $\checkmark$ & $\checkmark$ & & 33 \\
\hline PS22 & Tax break for secondary materials manufacturers and suppliers & $\checkmark$ & $\checkmark$ & $\checkmark$ & $\checkmark$ & 33 \\
\hline PS23 & Waste minimization planning as a competitive advantage in public contract bidding & $\checkmark$ & $\checkmark$ & $\checkmark$ & $\checkmark$ & 8 \\
\hline
\end{tabular}

${ }^{b}$ Number of codes describes the number of time that the keywords/codes producing the factors emanated in the data. 
${ }^{a}$ BREEAM: Building Research Establishment Environmental Assessment Method

\subsection{Quantitative Data Collection}

In order to test wider applicability and acceptability of the findings of this study, it is important that generalizability of the measures to the experts within the industry be established. As such, a further quantitative research was carried out. The qualitatively established factors were put into a questionnaire survey, as this means of data collection have tendency of reaching large audience with cost effectiveness (Walliman and Baiche, 2005). The questionnaire consists of the 23 policy suggestions in Table 2 on a Likert Scale of 1 to 5, where 1 represents strongly disagree and 5 represents strongly agree.

Weaknesses of positivist research, such as construct validity, were mitigated using pilot test. Seven respondents participated in the pilot test consisting of three architects, two Project Managers and two engineers. The purpose of the pilot study was to test clarity of language, layout, degree of depth, logic of the questions, and to perform a preliminary check of the proposed statistical analysis. Feedback from the pilot study further helped in improving the questionnaire design. Using the list of top 100 architecture and construction firms as a sampling frame, a copy of pilot tested and improved questionnaire was sent to each of the firms, yielding initial responses of 49 completed questionnaires. After a series of e-mail reminders, an additional 14 responses were received, resulting in a response rate of $63 \%$. Out of the 63 returned questionnaires, two were excluded from data analysis, as they were incomplete and unsuitable for further analysis. As such, this study enjoyed $61 \%$ response rate, which is within good response rate according to Fincham (2008). Table 3 shows the demographic distribution of the respondents. It was ensured that none of the focus group participants was involved in the quantitative study.

Table 3: Demography of the respondents

\begin{tabular}{|c|c|}
\hline Variables & Sample size \\
\hline Number of Respondents & 63 \\
\hline \multicolumn{2}{|l|}{ Profession/Job roles } \\
\hline Architects/design managers & 13 \\
\hline Civil/Structural Engineers & 8 \\
\hline Project Managers & 9 \\
\hline Quantity surveyors & 10 \\
\hline 5 MEP Professionals & 6 \\
\hline $6 \quad$ Waste Managers & 10 \\
\hline 7 Others (BIM Managers, Procurement officers, etc.) & 5 \\
\hline
\end{tabular}




\subsection{Quantitative Data Analysis and Findings}

Quantitative data analysis was carried out through a number of statistical analyses, which are further justified and discussed in this section.

\subsubsection{Reliability Analysis}

When using Likert scale on a questionnaire, it is important that reliability of the research instrument be tested using Cronbach's alpha coefficient (Nunnally and Bernstein, 2007; Yockey, 2008). Using SPSS version 22, the Cronbach's alpha coefficient for this study is 0.859 . With this value, the data used for this study shows a good reliability and internal consistency of the criteria. This is in line with George and Mallery (2003) who posit that a Cronbach alpha value of 0.7 is acceptable, while 0.8 shows a very good level of internal consistency. Cronbach Alpha's if item deleted was also used to remove factors that do not contribute to the high value of the coefficient (Field, 2009).

\subsubsection{Descriptive Mean Testing}

In order to ensure that only relevant factors are included in the factor analysis, descriptive mean testing was performed. Out of all the 23 policy suggestions, only one measure (PS20), "requirement for display of content of recycled materials/contents in products", has its mean score less than 3.5, and it was excluded from further analysis. This means that all policy suggestions that were used in further analysis are important for engendering waste diversion from landfill. Table 4 contains the mean value for each of the suggested policy measures.

\subsubsection{Exploratory Factor Analysis.}

Exploratory factor analysis was used to replace the 22 Policy Suggestions (PS) with a few number of uncorrelated key policy measures that are capable of engendering waste diversion from landfill. Using SPSS 22, KMO, Bartlett's test value and coefficient matrix for this study are 0.667, 1.775E-27 and 1.34E-4 respectively, confirming suitability of the data for factor analysis (Tabachnick and Fidell, 2001; Field, 2009).

As recommended by Field (2009), diagonal of anti-imaging matrix was examined to determine and exclude any factor having a diagonal value less than 0.5 . This led to a removal of one factor from further factor analysis. The removed factor is the PS18 on table 2, which is "improved database management for construction wastes and their reusability". Principal component analysis and Varimax analysis were used for factor extraction and rotation respectively. The results produced a six policy categories that are required for diverting construction waste from landfill. One measure that loaded significantly in two 
factors (PS23) was dropped as suggested by Tabachnick and Fidell (2001). The result indicated that the six-factor solution accounted for $89.089 \%$ of total variance. As further shown in table 4 , the factors were interpreted and labelled based on the measures that made up the groups as below:

1. Policy measure 1: Tax breaks and Incentives

2. Policy measure 2: Increased Target of Design Stage

3. Policy measures 3: Extension of Sustainable Design Appraisal system

4. Policy measures 4: Increased stringency of Existing Legislative Measures

5. Policy measures 5: Increased stringency of Fiscal provisions

6. Policy measures 6: Facilitation of Waste Preventive Measures 
Table 4: Exploratory factor analysis, mean test and reliability analysis results

\begin{tabular}{|c|c|c|c|c|c|c|}
\hline & Extracted and Rotated Components & $\begin{array}{l}\text { Eigen } \\
\text { Value }\end{array}$ & $\begin{array}{l}\% \text { of } \\
\text { variance }\end{array}$ & $\begin{array}{l}\text { Factor } \\
\text { loading }\end{array}$ & $\begin{array}{l}\text { Mean } \\
\text { Value }\end{array}$ & $\begin{array}{l}{ }^{a} \text { Cronbach's alpha if } \\
\text { item deleted }\end{array}$ \\
\hline 1 & Tax breaks and Incentives & 5.527 & 18.286 & & & \\
\hline PS 22 & Tax break for secondary materials manufacturers and suppliers & & & 0.825 & 4.48 & 0.755 \\
\hline PS21 & Tax break for waste treatment equipment & & & 0.824 & 4.41 & 0.726 \\
\hline PS3 & Award of points for the use of steel hoarding, formworks and dry walling & & & 0.594 & 3.95 & 0.847 \\
\hline PS4 & Award of points for the use of Just in Time (JIT) Procurement system & & & 0.690 & 3.79 & 0.857 \\
\hline 2 & Increased Target of Design Stage & 2.446 & 17.029 & & & \\
\hline PS2 & Deconstructability and deconstruction plan as a part of design documents & & & 0.705 & 4.36 & 0.851 \\
\hline PS15 & Increased consideration of design stages rather than the actual construction & & & 0.713 & 3.85 & 0.856 \\
\hline PS10 & Consider possibility of design freeze and contract completion before construction & & & 0.675 & 4.67 & 0.848 \\
\hline PS11 & Dimensional coordination \& specification of standard materials sizes to be required & & & 0.637 & 3.84 & 0.853 \\
\hline 3 & Extension of Sustainable Design Appraisal system & 1.953 & 14.338 & & & \\
\hline PS12 & Allocation of points for use of pre-assembled/modular system for large-scale projects & & & 0.828 & 3.80 & 0.855 \\
\hline PS1 & Allocation of more points to waste in design appraisal tools such as BREEAM & & & 0.605 & 4.51 & 0.850 \\
\hline PS16 & Collaborative contractual system such as IPD to be rewarded by points allocation & & & 0.602 & 4.48 & 0.852 \\
\hline PS7 & Take back scheme to become part of construction procurement requirements & & & 0.824 & 4.11 & 0.853 \\
\hline 4 & Increased stringency of Existing Legislative Measures & 1.585 & 13.599 & & & \\
\hline PS5 & Integrate CWM into the assessment of construction contractor & & & 0.586 & 4.31 & 0.857 \\
\hline PS6 & Employment of a dedicated site worker for waste management to be required & & & 0.642 & 4.03 & 0.851 \\
\hline PS8 & Requirement for the use of a proportion of secondary materials in every projects & & & 0.653 & 3.90 & 0.851 \\
\hline 5 & Increased stringency of Fiscal provisions & 1.460 & 12.982 & & & \\
\hline PS14 & Increasing landfill disposal fee and use of the excess fees as incentives & & & 0.772 & 4.05 & 0.854 \\
\hline PS9 & Raising fees for mixed wastes and reducing fees for separated waste disposal & & & 0.590 & 4.16 & 0.858 \\
\hline PS13 & Increasing aggregate tax and introduction of tax for disposing reusable materials & & & 0.556 & 4.28 & 0.857 \\
\hline 6 & Facilitation of Waste Preventive Measures & 1.348 & 12.856 & & & \\
\hline PS17 & Enhance information about quality, availability and benefits of secondary materials & & & 0.870 & 4.03 & 0.856 \\
\hline PS19 & Developing market structure and easy access to recycled materials & & & 0.763 & 4.34 & 0.854 \\
\hline
\end{tabular}




\section{Discussion}

This section discusses the six key factors that underlie the policy suggestions, which emanated from the initial exploratory study.

\subsection{Tax break and Incentives}

In concurrence with intervention theory, Kluger and DeNisi (1996) suggests that incentives and deterrence are key tools for encouraging or discouraging certain behavioural patterns among the populace. Apart from imposing stringent legislations and fiscal policies, the use of incentives and tax break is a key measure for achieving construction waste minimization. Cooper (1996) posits that stringent waste management legislation and fiscal policies would remain ineffective if there are no ways of facilitating such practices. In line with this, Bartl (2014) opined that since waste generation is in itself a positive factor of economic growth, while also serving as a source of business, sophisticated incentives would be required for decoupling economic growth from waste generation. This finding is similar to the earlier suggestion of economic carrot, which is deemed a way of moving waste management practices up the ladder of waste hierarchy within the UK (Wilson, 1996). A similar study in Taiwan also suggests the need for incentivising waste management practices, as a means of encouraging waste reduction (Tsai and Chou, 2004). Despite earlier studies not being specific to the construction industry, the concurrence of this finding with the studies suggests that the policy measures that have proven successful in municipal waste management could also be applied to the construction industry.

Although the focus group participants agreed that such incentives and tax breaks need to be financed from penalties and fines for inadequate sustainability practices, it was stressed that the use of economic carrots is an effective way of encouraging sustainability habits in the construction industry.

Like site workers, contractors are motivated by the availability of incentives for sustainability practices (Teo and Loosemore, 2001). This is because, unlike government that is mainly concerned about environmental aspects of waste minimization, the contractors are more influenced by financial benefits of waste minimization (Ajayi et al., 2015). This is notwithstanding country or regions, as evidence from both developed and developing countries suggests the effectiveness of incentives in engendering waste minimization practices (cf. Tsai and Chou,2004; Wilson, 1996). As such, incentivising waste management practices and resource conservation is an effective measure for engendering such practices within the industry. For instance, low use of recycled construction materials is attributed to its high cost, despite its perceived low quality (Oyedele et al., 2014). Direct subsidisation of secondary materials, provision of a tax break for its manufacturers and suppliers, and provision of economic incentives for waste management infrastructures are suggested by the focus group participants. It was stressed that 
such move would lower cost of secondary materials and enhance its popularity, thereby enhancing its use in construction projects.

\subsection{Increased Target of Design Stage}

There has been consensus across literature that design stage is very crucial in construction waste minimization (cf. Ekanayake and Ofori, 2004; Wang et al., 2014; Akinade et al., 2015). By taking adequate waste minimization strategies during the design stage, about a third of construction waste could be prevented (Innes, 2004). This implies that efforts to tackle waste at design stage could result in its substantial reduction. Despite the understanding that design stage is decisive in construction waste minimization, most strategies target construction stage where preventive measures are already late. These current practices fail to be in line with the concept of intervention, which is expected to consider the whole system (Argyris, 1970). As such, for waste management policy intervention to effectively divert construction waste from landfill, it must consider the whole process of project delivery, among which design stage is crucial.

Although the sustainable design appraisal system being used across nations - such as BREEAM (Building Research Establishment Environmental Assessment Method), LEED (Leadership in Energy and Environmental Design), etc. - have considered various design practices for environmental sustainability, they are yet to consider options for designing out waste. Similarly, like other nations, the UK waste management policies have concentrated on construction stage, leaving out the stage where waste could be designed out. Thus, this study suggests the need for increasing target of design stage in future waste management policies.

In line with this finding, WRAP (2009) suggests that as demolition waste contributes a large proportion of construction waste, an effective approach to reduce $C \& D$ waste in landfill is by considering deconstruction during the design stage. Osmani (2012) also argued that waste management legislations have not addressed the design stage, despite its importance in preventing waste. As the waste effectiveness of the construction industry depends on the extent to which waste is designed out (Ajayi et al., 2015), consideration of design stage in waste management legislation would reduce waste intensiveness of the construction industry.

\subsection{Extension of Sustainable Design Appraisal system}

Sustainable design appraisal tools have remained an effective mechanism for driving sustainability practices across the globe. They set best practice standards for environmental performance of buildings throughout its project delivery processes as well as during operational stage. Since BREEAM came into operation in 1990, several other environmental assessment tools have been developed in other nations, 
partly due to its effectiveness (Nguyen and Altan, 2011). For instance, LEED was developed in the US in 1998, while the Japanese CASBEE (Comprehensive Assessment System for Built Environment Efficiency) became operational in 2001.

With the increasing popularity of the sustainability appraisal tools, this study suggests allocation of higher points to waste management practices. This experts' suggestion further corroborate the relevance of intervention theory to environmental issues, especially as it falls in line with the tenet of free choice which empowers the practitioners with various options of achieving points during design appraisal process.

It was raised that apart from dedicated waste management policies and regulations, allocation of more points to waste in the existing and widely used sustainability appraisal tool could further engender waste management practices in the construction industry. This corroborates earlier findings by Dainty and Brookes (2004), which suggests that inclusion of waste in sustainable design appraisal tools, such as BREAM, is a key motivator for designing out waste. A similar study in Japan (Tam et al., 2004) also conclude that green construction appraisal tools are key drivers of construction waste minimization. Notwithstanding these prior studies, no significant importance has been attached to waste in such sustainable design appraisal tools as the UK BREAAM and the US LEED. Most appraisal systems have only considered the extent of material sorting, reuse, and recycling that are incorporated into the management plan (Cha et al., 2009). Currently, $8.5 \%$ of possible $110 \%$ addresses waste management in BREAAM, while $6.4 \%$ of possible $100 \%$ address waste management in the Code for Sustainable Homes. Increasing the points allocated to waste means that waste management could be taken as important as land use, materials, pollution, energy and management, which are given $10 \%, 13.5 \%, 10 \%$, $15 \%$ and $12 \%$ respectively in BREEAM.

\subsection{Increased stringency of Legislative Measures}

As the legislative measures continually drive construction waste management, the respondents opined that increasing stringency of such provision remains the most viable way of stimulating waste diversion from landfill. Particularly, this measure could essentially coerce the industry experts into environmental consciousness, thereby serving the main purpose of government intervention in environmental issues. The experts suggest compulsion of certain waste management measures, which have been proven to enhance waste mitigation. In line with these policy suggestions, a study by Lu and Tam (2013) suggests that while construction waste management policies are successfully driving waste management efforts; there is a need for increasing the stringency of such measures in Hong Kong. Krevitz (2000) suggests that legislation is essential to shaping waste landfilling in the US. Al-Hajj and Hamani (2011) made similar suggestions for the UAE construction industry, while Bartl (2014) suggests similar solutions for the EU construction industry. 
Corroborating this study, earlier findings suggest that an availability of dedicated site team or subcontract package for on-site waste management reduces the waste output of construction projects (Dainty and Brooke, 2004). Similarly, the relevance of take back scheme in reducing construction waste has been stressed in literature (Al-Hajj and Hamani, 2011). It involves an agreement between the project team and materials suppliers so that the latter would take back unused materials at the end of construction activities. Evidence shows that by having such provisions in place, waste that is usually caused by materials leftover would not only be prevented, substantial cost savings could be made (Cha et al., 2009). As such, considering the waste efficient contract clause in waste management regulations would engender cost savings and waste diversion from landfill.

In line with the issues raised by the respondents, the literature suggests that albeit the environmental benefits of secondary materials and the government's agitation for its use in construction, its use is yet to become a commonplace in the construction industry (Mansikkasalo et al., 2014). Although the industry subscribes to waste recycling, its reuse has been hindered by many factors such as its rare specification by designers, inadequate information about the materials and its negative perception, among others (Oyedele et al., 2014). A government policy that requires the use of a certain proportion of recycled materials per projects would, therefore, encourage its wide adoption in the industry. Thus, assigning points to proven waste mitigation techniques would engender its practices and subsequent waste minimization (Lu and Tam, 2013).

\subsection{Increased stringency of Fiscal provisions.}

Since the introduction of landfill tax in 1996, influences of tax and fines on construction waste minimization has become clear. The impartial tax measure ensures that tax is paid per unit tonne of waste deposited in landfill sites. Findings from the factor analysis suggest increased the stringency of the existing fiscal measures. This is especially required, as the financial implications of waste management strategy determine its acceptability in the construction industry. Although this factor is at variance with the tenet of free will, as advocated by the intervention theory, it falls well in line with a purpose of intervention, which might seek to coerce a group of people into accepting the intervenors' idea (Argyris, 1970). This finding corroborates earlier suggestion of economic sticks, as means of penalising poor waste management practices (Wilson, 1996). 
Unlike cost, time and quality, construction waste management receives less attention in the construction industry. Increasing cost of waste landfilling as well as the cost of mixed waste would ensure waste separation, reuse and recycling. As the contractors are more concerned about cost implications of waste disposal (Cooper, 1996), such measure is capable of engendering waste management practices. Thus, policies that impose financial penalties on poor waste performance is requisite to reducing waste generated by construction activities.

\subsection{Facilitation of Waste Preventive Measures}

Apart from strict regulations, the effectiveness of construction waste mitigation policies depends on the level of economic incentives and enablers available (Cooper, 1996). The finding compares Asnani and Zurbrugg (2007), which suggests that provision of incentives and enablers are key to effective solid waste management policies in India. Similar UK studies also posit that provision of incentives and enablers is requisite to the effectiveness of waste management policies (Wilson, 1996). This means that notwithstanding the economic state of a nation or its citizen's awareness of environmental sustainability, provision of relevant enablers is indispensable to the effectiveness of sustainability policies.

As suggested by the respondents, this study stresses that together with taxes, stringent legislation and various penalties, waste minimization and resource efficiency should also be facilitated through various enablers. For instance, to encourage the use of recycled materials in the industry, there is a need for facilitating information and market structures for the materials (Oyedele et al., 2014). This would ensure adequate awareness of the materials, as well as its wider acceptability and use, thereby supporting waste diversion from landfill. As such, each legislative and fiscal measure is to be facilitated through proportionate enablers and economic incentives capable of enhancing compliance with the legislative provisions. This particular measure is consistent with the concept of intervention theory, which posits that a valid and valuable intervention should provide adequate support to the extent that a client system should be able to carry out its businesses without total dependence on the intervenor (Argyris, 1970). In this case, provision of adequate enablers will empower the industry experts to mitigate waste, without been necessarily coerced by the government.

\section{Conclusions}

Legislation and fiscal policies have remained the key drivers of sustainability across the construction industry. Particularly, little success recorded in construction waste diversion from landfill has been attributed to various waste management regulations, tax and fines associated with wasteful behaviour in the industry. It has often been suggested that reducing waste to the landfill does not only require improvement on existing waste management regulations, policies and fiscal framework; there is a need 
for adequate inputs from the construction professionals. Albeit these claims, there has been a paucity of literature that corroborates government's efforts in formulating or improving existing waste management strategies. As a first of its kind, this study explores industry practitioners' viewpoints on effective policies for minimising waste landfilled by the construction industry.

As a means of stimulating strategic policies capable of enhancing the waste effectiveness of the construction industry, this study suggests that as design stage is very crucial to waste minimization, legislative and fiscal policies should target measures for designing out waste. This should be done in addition to increased stringency of existing legislative and fiscal policies. While such measures as take back scheme, use of recycled aggregates, employment of dedicated site waste managers are recommended as an improvement to legislative provisions, increasing landfill tax, aggregate tax and cost of landfilling mixed waste are required as fiscal measures. Sustainable design appraisal tools, such as BREEAM, could also facilitate construction waste minimization by allocating points to waste efficient construction methods and practices. In order to ensure an effectiveness of the legislative and fiscal policies, the government is expected to provide incentives and enablers, while also encouraging waste minimization through tax breaks and incentives.

\subsection{Implications for policy direction}

Based on its purpose and findings, this study has implications for policy making concerning construction waste management regulations and policies across the globe, especially as the findings of the study is corroborated by other findings from across various nations. As evidence suggests that waste minimization is mainly stimulated by legislative and fiscal measures, increasing the stringency of the existing measures is required on the part of the government. This could be achieved by including proven waste efficient procurement construction methods and processes in legislative measures or by allocating points to such approaches in sustainable design appraisal tools such as BREAAM and LEED. Increasing fine for poor waste performance, such as landfilling and mixed waste, and provision of tax breaks and incentives for good waste performance and waste management businesses are also required for enhancing waste diversion from landfill. Corroborating stringent waste management policies with enablers will enhance the effectiveness of such policies. For instance, as the government is encouraged to require the use of secondary materials for every project, efforts should be made to provide market structure for the products, while also providing adequate information about its quality and benefits. By embracing both carrot and stick measures suggested in the study, substantial construction waste would be diverted from landfill.

As a typical study investigating policy related to environmental sustainability, this study demonstrates the relevance of intervention theory at a holistic level. Although some of the suggested measures are meant to serve as incentives and deterrence towards improving construction waste diversion from 
landfill, most of the suggested measures are in tandem with the tenet of intervention theory. The study shows that at a unitary level of environmental policymaking, there is a tendency for a single policy to fail in providing free choice while obeying other requisites for valid intervention as postulated by the intervention theory. Nonetheless, the study suggests that a set of policy measures aimed at a particular goal are meant to obey all the provisions of the theory at a holistic level. In the case of waste management policy interventions, as exemplified in this study, the suggested policy measures captured the whole process of project delivery, while it also obeys the tenet of free choice in a way that the contractors could use other techniques for mitigating waste generated by construction activities. Thus, this study exemplifies the validity and usefulness of intervention theory as a means of guiding environmental policy interventions.

\subsection{Limitations and future directions}

Notwithstanding that the study has been carried out within the EU context, evidence from other regions suggest that the policy suggestions are also relevant to other parts of the world. Nonetheless, other studies could explore legislative and policy measures capable of engendering waste minimization outside the region, as a means of establishing an area of similarity and disparity with this study. Data for this study has been collected from experts in the UK construction industry and no government department and NGOs was surveyed. Further studies could explore the perception of experts from other nations within the EU and beyond, and views of government departments and NGOs could be explored.

Due to the need for in-depth exploration of new legislation and policy direction, this study found relevance in descriptive interpretive approach as a qualitative method of enquiry. As such, preference was given to in-depth exploration at qualitative level rather than the length at quantitative stage. Quantitative approach has only been used for the purpose of validity and factor exploration. Future studies could examine critical success factors from the identified strategies and test for wider acceptability and generalizability of the waste management policies within the UK and beyond. Quantitative model of effects of the existing and proposed policy measures could be evaluated by further studies. As the cost benefit analysis of the proposed policy has not been considered in this study, financial costs of the suggested palliative measures could be established by further studies. In order to ensure the effectiveness of waste management policies, implementation of the suggested measures should consider and factor in likely unintended effects that might come along as byproducts of the policy design. 


\section{Acknowledgement}

The authors would like to express their sincere gratitude to Innovate UK and Balfour Beatty PLC for providing the financial support for the research through grant (Application) No $22883-158278$ and File No 101346.

\section{References}

Adams, K., Johnson P., Thornback, J., \& Law C., (2011). An Action Plan for halving construction, demolition and excavation waste to landfill. UK: WRAP.

Adjei, S., Ndekugri, I. and Ankrah N. (2013). Review of construction and demolition waste management legislation in the UK. In: Proceedings of the construction, building and real estate research conference of the Royal Institution of Chartered Surveyors, New Delhi, India. $10^{\text {th }}-12^{\text {th }}$ September 2013.

Ajayi, S. O., Oyedele, L. O., Bilal, M., Akinade, O. O., Alaka, H. A., Owolabi, H. A., \& Kadiri, K. O. (2015). Waste effectiveness of the construction industry: Understanding the impediments and requisites for improvements. Resources, Conservation and Recycling, 102, 101-112.

Ajayi, S.O., Oyedele, L.O., Akinade, O.O., Bilal, M., Owolabi, H.A., and Alaka, H.A. (2014). Ineffectiveness of construction waste management strategies: Knowledge gap analysis. In: Okeil, M. (2014). Smart, sustainable and healthy city, Proceedings of the First International Conference of the CIB Middle East and North Africa Research Network (CIB-MENA 2014), pp. 261 - 280.

Akinade, O.O., Oyedele, L.O., Bilal, M., Ajayi, S.O., Owolabi, H.A., Alaka, H.A. \& Bello, S.A., (2015). Waste minimisation through deconstruction: A BIM based Deconstructability Assessment Score (BIM-DAS). Resources, Conservation and Recycling, 105, pp.167-176.

Al-Hajj, A., \& Hamani, K. (2011). Material waste in the UAE construction Industry: Main causes and minimization practices. Architectural Engineering and Design Management, 7(4), 221-235.

Asnani, P.U. and Zurbrugg, C., 2007. Improving municipal solid waste management in India: A sourcebook for policymakers and practitioners. World Bank Publications.

Bingham, L. B., Nabatchi, T., \& O'Leary, R. (2005). The new governance: Practices and processes for stakeholder and citizen participation in the work of government. Public Administration Review, 65(5), 547-558.

Braun, V., \& Clarke, V. (2006). Using thematic analysis in psychology. Qualitative research in psychology, 3(2), pp. 77-101.

BRE (2003). Construction and Demolition Waste: Good Buildings Guide 57 Part 1. UK: Building Research Establishment

Cha, H. S., Kim, J., \& Han, J. Y. (2009). Identifying and assessing influence factors on improving waste management performance for building construction projects. Journal of Construction Engineering and Management, 135(7), 647-656. 
Cooper, J. C. (1996). Controls and incentives: A framework for the utilisation of bulk wastes. Waste Management, 16(1), 209-213.

Creswell, J. W. (2013). Qualitative inquiry and research design: Choosing among five approaches, $3^{\text {rd }}$ edition. Thousand Oaks: Sage.

Dainty, A.R.J., \& Brooke, R.J. (2004). Towards improved construction waste minimisation: A need for improved supply chain integration? Structural Survey, 22(1), 20-29.

Department for Environment Food and Rural Affairs - DEFRA, (2007). Waste Strategy for England 2007. London: DEFRA.

Department for Environment Food and Rural Affairs - DEFRA, (2013). Waste prevention programme for England: Overview of evidence - A Rationale for waste prevention in England. London: DEFRA.

Directive 2008/98/EC of the European Parliament and of the Council of 19 November 2008 on waste and repealing certain Directives [2008]. OJ L312/3.

Field, A. (2013). Discovering statistics using IBM SPSS statistics, $3^{\text {rd }}$ edition. London: SAGE.

Fincham, J. E. (2008). Response rates and responsiveness for surveys, standards, and the Journal. American Journal of Pharmaceutical Education,72(2), 43.

HM Government, (2008). Strategy for Sustainable Construction. London: Department for Business, Enterprise \& Regulatory Reform.

Innes, S. (2004). Developing tools for designing out waste pre-site and onsite. In: Proceedings of Minimising Construction Waste Conference: Developing Resource Efficiency and Waste Minimisation in Design and Construction, New Civil Engineer, London, UK, October 2004.

Krevitz, E., 2000. Not in My Landfill: Virginia and the Politics of Waste Importation. Policy Perspectives, 7(2), pp.5-13.

Lu, W., \& Tam, V. W. (2013). Construction waste management policies and their effectiveness in Hong Kong: A longitudinal review. Renewable and Sustainable Energy Reviews, 23, 214-223.

Mansikkasalo, A., Lundmark, R., \& Söderholm, P. (2014). Market behavior and policy in the recycled paper industry: A critical survey of price elasticity research. Forest Policy and Economics, 38, $17-29$.

Merriam, S. B. (1998). Qualitative research and case study applications in education. Revised and expanded from" case study research in education." San Francisco, CA: Jossey-Bass Publishers

Nguyen, B. K., \& Altan, H. (2011). Comparative review of five sustainable rating systems. Procedia Engineering, 21, 376-386.

Nunnally, J.C., \& Bernstein, I.H. (2007). Psychometric Theory, $3^{\text {rd }}$ edition. New York: McGraw-Hill.

Osmani, M., Glass, J. and Price, A.D., 2006. Architect and contractor attitudes to waste minimisation. Proceedings of the Institution of Civil Engineers: Waste and Resource Management, 159, pp. 65-72 
Oyedele, L. O. (2012). Avoiding performance failure payment deductions in PFI/PPP projects: Model of critical success factors. Journal of Performance of Constructed Facilities, 27(3), 283-294.

Oyedele, L. O., Ajayi, S. O., \& Kadiri, K. O. (2014). Use of recycled products in UK construction industry: An empirical investigation into critical impediments and strategies for improvement. Resources, Conservation and Recycling, 93, 23-31.

Oyedele, L.O., Regan, M., Meding, J.V., Ahmed, A., Ebohon, O.J., and Elnokaly, A. (2013). Reducing waste to landfill in the UK: identifying impediments and critical solutions. World Journal of Science, Technology and Sustainable Development, 10(2), pp. 131 - 142.

Pitt, M., Tucker, M., Riley, M., \& Longden, J. (2009). Towards sustainable construction: Promotion and best practices. Construction innovation, 9(2), 201-224.

Polkinghorne, D. E. (1989). Phenomenological research methods. In: Hailing, S., \& Valle, R. (1989). Existential-phenomenological perspectives in psychology, pp. 41-60. New York: Springer.

Read, A. D., Phillips, P., \& Robinson, G. (1997). Landfill as a future waste management option in England: The view of landfill operators. Resources, conservation and recycling, 20(3), 183-205.

Shen, L. Y., \& Tam, V. W. (2002). Implementation of environmental management in the Hong Kong construction industry. International Journal of Project Management, 20(7), 535-543.

Solís-Guzmán, J., Marrero, M., Montes-Delgado, M. V., \& Ramírez-de-Arellano, A. (2009). A Spanish model for quantification and management of construction waste. Waste Management, 29(9), $2542-2548$.

Tabachnick, B. G., \& Fidell, L. S. (2001). Using multivariate statistics, $5^{\text {th }}$ edition. Bolton: Pearson.

Tam, C.M., Tam, V.W. and Tsui, W.S., 2004. Green construction assessment for environmental management in the construction industry of Hong Kong. International Journal of Project Management, 22(7), pp.563-571.

Tam, V. W. (2008). On the effectiveness in implementing a waste-management-plan method in construction. Waste management, 28(6), 1072-1080.

Teo, M. M. M., \& Loosemore, M. (2001). A theory of waste behaviour in the construction industry. Construction Management \& Economics, 19(7), 741-751.

Tsai, W.T. and Chou, Y.H., 2004. Government policies for encouraging industrial waste reuse and pollution prevention in Taiwan. Journal of Cleaner Production, 12(7), pp.725-736.

Van Manen M. (1990). Researching lived experience: Human science for an action sensitive pedagogy. London, Ontario: Althouse.

Walliman, N. and Baiche, B. (2005). Your research project: a step by step guide for the first time researcher, $2^{\text {nd }}$ edition, London: SAGE.

Wang, J., Li, Z., \& Tam, V. W. (2014). Critical factors in effective construction waste minimization at the design stage: A Shenzhen case study, China. Resources, Conservation and Recycling, 82, 1-7.

Wilson, D.C., 1996. Stick or carrot?: The use of policy measures to move waste management up the hierarchy. Waste Management \& Research,14(4), pp.385-398. 
WRAP, (2009). "Designing out waste: A design team guide for buildings" (online). Available at: http://www.modular.org/marketing/documents/DesigningoutWaste.pdf. [Accessed: $3^{\text {rd }}$ March 2014].

Yockey, R. D. (2010). SPSS demystified: A step by step approach, $2^{\text {nd }}$ edition. Upper Saddle River, NJ: Prentice Hall Press.

Yuan, H. (2013). A SWOT analysis of successful construction waste management. Journal of cleaner production, 39, 1-8.

Yuan, H., \& Shen, L. (2011). Trend of the research on construction and demolition waste management. Waste management, 31(4), 670-679. 